Efficient Vol 2 (2) (2019): 387-394 DOI: https://doi.org/10.15294/efficient.v2i2.30797

\title{
EFFICIENT
}

Indonesian Journal of Development Economics https://journal.unnes.ac.id/sju/index.php/efficient

\section{Analisis Pelayanan Publik Bidang Transportasi untuk Difabel di Kota Semarang}

\author{
Chusna Adzanin Therawati ${ }^{1 凶}$, Rusdarti $^{2 凶}$ \\ Jurusan Ekonomi Pembangunan, Fakultas Ekonomi, Universitas Negeri Semarang \\ Permalink/DOI: https://doi.org/10.15294/efficient.v2i2.30797
}

Received: December 2018 ; Accepted: March 2019; Published: Juny 2019

\begin{abstract}
This research is conducted with the aim to find out the quality standards of Trans Semarang which are diffable friendly. This research uses quantitative approach. The samples are the blind and the disabled who had used Trans Semarang in the amount of 5 people. The variables of this study are Trans Semarang facilities and the internal and the external constraints. The Data collection techniques use observation, interviews and documentation methods. This study uses percentage descriptive data analysis. The results of the study show that the Trans Semarang facility is still not difabel friendly and still cannot be utilized optimally. The Trans Semarang facility is still not diffable friendly because there are still many shelters that are not suitable, such as not having a ramp, no handles, slippery, steep, the existence of trees / poles barrier and damaged. There are still around 178 pieces or around $60.9 \%$ of shelters that are not diffable friendly. The recommendations of this research are improving the shelter to be diffable friendly, completing the access for all types of diffables, increasing the competency of officers and the awareness of the public about the existence of the Trans Semarang shelter
\end{abstract}

Keywords: Public Service, Trans Semarang, Difabel

\begin{abstract}
Abstrak
Penelitian ini dilakukan dengan tujuan untuk mengetahui standar kualitas Trans Semarang yang ramah difabel. Pendekatan penelitian ini menggunakan metode penelitian kuatitatif. Sampel yang dipakai adalah tuna netra dan tuna daksa yang pernah menggunakan Trans Semarang yaitu sebanyak 5 orang. Variabel penelitian ini adalah fasilitas Trans Semarang dan kendala internal serta eksternal. Teknik pengambilan sampel penelitian ini menggunakan purposive sampling dengan kriteria-kriteria yang ditentukan oleh peneliti. Teknik pengumpulan data menggunakan metode observasi, wawancara dan dokumentasi. Penelitian ini menggunakan analisis data deskriptif persentase. Hasil penelitian menunjukkan bahwa fasilitas Trans Semarang masih belum ramah difabel dan masih belum bisa dimanfaatkan secara maksimal. Fasilitas Trans Semarang masih belum ramah difabel karena masih banyak shelter yang belum sesuai diantaranya belum memiliki ramp, belum ada pegangan, licin, curam, terdapat pohon/tiang penghalang, dan rusak. Masih ada sekitar 178 buah atau sekitar $60.9 \%$ shelter yang masih belum ramah difabel. Rekomendasi untuk penelitian ini adalah adanya perbaikan shelter agar ramah difabel, melengkapi akses untuk semua jenis difabel, kompetensi petugas lebih ditingkatkan serta kesadaran masyarakat tentang adanya shelter Trans Semarang.
\end{abstract}

Kata Kunci: Pelayanan Publik, Trans Semarang, Difabel

How to Cite: Therawati, C., \& Rusdarti, R. (2019). Analisis Pelayanan Publik Bidang Transportasi untuk Difi Semarang. EFFICIENT Indonesian Journal of Development Economics, 2(2), https://doi.org/10.15294/efficient.v2i2.30797

(C) 2019 Semarang State University. All rights reserved

\footnotetext{
Alamat Korespondensi :

Alamat: Gedung L2 Lantai 2 FE Unnes

Kampus Sekaran, Gunungpati, Semarang, 50229

E-mail : ctherawati.150195@gmail.com
}

ISSN 2655-6197 


\section{PENDAHULUAN}

Pelayanan publik merupakan salah satu bentuk pengabdian pemerintah kepada masyarakat dalam memenuhi setiap kebutuhan yang diperlukan masyarakat oleh sebab itu pelayanan publik harus memperhatikan kebutuhan masyarakat, dengan begitu maka setiap kebutuhan dapat terpenuhi. Kebutuhan pelanggan dapat terpenuhi jika pelayanan publik dapat memberikan pelayanan yang memenuhi enam dari sepuluh indikator pelayanan yang baik berdasarkan teori yang dikemukakan oleh Gasperz dalam Azis Sanapiah (2000:15) yaitu "kepastian waktu pelayanan, akurasi pelayanan, kesopanan dan keramahan, tanggung jawab, kelengkapan, dan kemudahan mendapatkan pelayanan”. Jika pelayanan yang diberikan telah memenuhi kriteria tersebut, maka dapat dikatakan kebutuhan telah terpenuhi sehingga dapat memberikan kepuasan kepada masyarakat.

Pemerintah sebagai penyedia layanan publik yang dibutuhkan oleh masyarakat harus bertanggung jawab dan terus berupaya untuk memberikan pelayanan yang terbaik demi peningkatan pelayanan publik. Disisi lain kepuasan masyarakat adalah tolak ukur dari keberhasilan pelayanan publik yang diberikan oleh penyedia layanan publik, oleh sebab itu pelayanan publik harus difokuskan pada pemenuhan kebutuhan masyarakat secara maksimal baik dari segi kualitas maupun kuantitasnya. Selain itu, kualitas layanan yang baik juga akan berpengaruh dengan kepedulian masyarakat terhadap layanan publik itu sendiri. Kepedulian masyarakat juga dapat menurun karena dipengaruhi oleh kurang maksimalnya pelayanan publik yang diberikan oleh pemerintah. Perlu di ingat bahwa keberhasilan otonomi daerah bukan hanya disebabkan oleh kemandirian keuangan daerah, akan tetapi kualitas pelayanan publik yang diberikan oleh pemerintah.

Berdasarkan Keputusan Menteri Pendayagunaan Aparatur Negara Nomor 63 Tahun 2003 tentang pedoman umum penyelenggaraan pelayanan publik seperti prosedur pelayanan, persyaratan pelayanan, kemampuan petugas pelayanan, kecepatan pelayanan, keadilan mendapatkan pelayanan, kepastian biaya pelayanan, dan kepastian jadwal pelayanan maka pemerintah memiliki konsekuensi untuk meningkatkan pelayanan dalam sektor pelayanan publik. Diharapkan aparat pemerintah di seluruh Indonesia melaksanakan pelayanan publik dengan baik sesuai apa yang diharapkan oleh masyarakat. Masih banyak yang perlu diperbaiki dari pelayanan publik yang ada di Indonesia ini, salah satunya daerah yang perlu perbaikan adalah Kota Semarang sebagai salah satu pelaksana pelayanan publik.

Kota Semarang merupakan ibu kota dari Provinsi Jawa Tengah dan menjadi salah satu kota besar di Indonesia. Kota Semarang sebagai kota besar akan memiliki peran yang sangat besar dalam melaksanakan pelayanan publik salah satunya adalah penyediaan fasilitas umum terutama untuk para penyandang disabilitas atau difabel yang menjadi salah satu prioritas dalam pelaksanaan pelayanan umum. Kaum difabel sebagai masyarakat yang harus mendapat perhatian khusus dalam memenuhi kebutuhan salah satunya dalam hal fasilitas umum yang berbeda dari masyarakat pada umumnya.

Berdasarkan data tabel 1. dapat diketahui bahwa jumlah total kaum difabel atau penyandang cacat mengalami peningkatan 
dari tahun 2011 sebanyak 2.784 orang menjadi 3.557 pada tahun 2012 dan untuk tahun selanjutnya jumlahnya tetap. Jumlah untuk tiap jenis cacat mengalami kenaikan pada tahun 2012 kecuali untuk jenis cacat mental yang mengalami penurunan. Jumlah penyandang cacat atau difabel di Kota Semarang yang banyak, harus didukung dengan fasilitas umum yang memadai pula karena kaum difabel memiliki hak yang sama dengan masyarakat normal seperti yang tertera pada Undang-undang 1945 Pasal 27 Ayat (2) yang menyebutkan bahwa "seluruh warga negara berhak atas pekerjaan dan penghidupan yang layak", yang berarti bahwa ada persamaan bagi setiap warga negara tanpa membedakan kondisi fisik.

Tabel 1. Jumlah Penyandang Cacat di Kota Semarang Tahun 2011-2015

\begin{tabular}{llllll}
\hline Jenis & 2011 & 2012 & 2013 & 2014 & 2015 \\
Cacat & & & & & \\
\hline Tubuh & 758 & 862 & 862 & 862 & 862 \\
Tuna & 390 & 806 & 806 & 806 & 806 \\
Netra & 280 & 667 & 667 & 667 & 667 \\
Mental & 980 \\
Tuna & 562 & 694 & 694 & 694 & 694 \\
Rungu & & & 528 & 528 & 528 \\
Ganda & 94 & 528 & 528 \\
Jumlah & 2.784 & 3.557 & 3.557 & 3.557 & 3.557 \\
\hline
\end{tabular}

Sumber : BPS Kota Semarang data diolah 2017

Trans Semarang merupakan salah satu sarana transportasi yang bisa digunakan untuk difabel karena dirancang agar ramah difabel dan dikelola oleh pemerintah, sedangkan sarana transportasi lain seperti angkutan umum lainnya tidak dirancang agar ramah difabel dan dikelola oleh swasta sehingga akan susah untuk disesuaikan dengan standar layanan publik. Akan tetapi, Trans Semarang yang seharusnya ramah difabel pada kenyatannya masih sulit diakses untuk difabel karena akses yang disediakan masih terbatas. Salah satunya dikeluhkan oleh seorang difabel Sugeng Widodo, Sugeng mengeluhkan sejumlah fasilitas umum, baik yang disediakan pemerintah maupun swasta, masih sulit diakses difabel. Beliau mencontohkan, shelter bus masih terlalu curam sehingga menyulitkannya ketika akan naik angkutan umum (Tribun Jateng, 07/11/2016). Selain Sugeng Widodo, Reza Aditia, salah satu penyandang difabel merasa kesulitan saat mengakses beberapa fasilitas umum yang ada, fasilitas BRT seperti tangga masih dianggap belum sesuai karena masih terlalu menukik dengan kemiringan 45 derajat (Media Jateng, 19/04/2016).

Menurut Keputusan Menteri Pekerjaan Umum No. 30/PRT/M/2006 tentang pedoman teknis fasilitas dan aksesibilitas pada bangunan gedung dan lingkungan, pada sarana transportasi angkutan umum untuk difabel harus memiliki jalur pendestrian, jalur pemandu, furniture jalan, ruang atau tempat duduk yang bisa digunakan dan ramp dengan kemiringan tertentu, tetapi pada kenyataannya semua itu masih jauh dari standar. Hal itu disebabkan karena masih banyak shelter BRT (Basic Rapid Transit) dan Trans Semarang yang tersedia tidak sesuai dengan peraturan.

Berdasarkan data yang diperoleh dari Dinas Perhubungan terkait kondisi shelter yang ada di Kota Semarang masih banyak 
shelter yang rusak, tidak layak dan tidak ramah difabel.

Tabel 2. Kondisi Shelter BRT

\begin{tabular}{llllr}
\hline No & Koridor & Jumlah & $\begin{array}{l}\text { Rusak, } \\
\text { nyaman, } \\
\text { ramah difabel }\end{array}$ & $\begin{array}{r}\text { tidak } \\
\text { tidak }\end{array}$ \\
\hline 1 & I & 82 & 42 \\
2 & II & 60 & 14 \\
3 & III & 46 & 16 \\
4 & IV & 52 & 42 \\
5 & V & 32 & 29 \\
6 & VI & 20 & 20 \\
Jumlah & 292 & 163 \\
\hline
\end{tabular}

Sumber: Dinas Perhubungan Kota Semarang data diolah 2017

Dari data diatas dapat bahwa dari 292 buah shelter yang ada terdapat 163 buah shelter yang rusak, tidak nyaman dan ramah difabel atau sekitar 55,8\%, dan hampir semua shelter portabel tidak ramah difabel. Hal ini membuktikan bahwa perencanaan pemerintah terkait pengadaan shelter portabel masih banyak kekurangan dan perencaan yang kurang matang. Terutama pada tahun 2017 penambahan dua koridor baru yaitu koridor $\mathrm{V}$ dan VI dengan menggunakan shelter portabel yang tidak ramah difabel.

Pelayanan sosial dan mobilitas para difabel kurang terpenuhi dengan layak dimana sebagian besar hambatan aksesibilitas masih banyak ditemukan berupa hambatan arsitektural dan prosedural. Pembangunan sarana transportasi yang dilakukan pemerintah dalam menerapkan peraturan pemerintah terkait layanan publik yang ramah difabel masih dianggap kurang maksimal. Sehingga hal ini memunculkan pertanyaan terkait permasalahan yang membuat pembangunan sarana transportasi tidak sesuai dengan peraturan pemerintah yang sudah ada.

\section{METODE}

Penelitian ini menggunakan jenis penelitian kuatitatif dengan pendekatan deskriptif. Desain penelitian yang digunakan adalah metode studi kasus (case study). Pendekatan kuatitatif deskriptif dengan metode studi kasus yang digunakan terkait dengan penelitian berupaya melakukan kajian pada suatu permasalahan dalam upaya menyediakan fasilitas sarana transportasi khususnya shelter BRT dan Trans Semarang yang ramah difabel. Populasi penelitian ini adalah difabel di Kota Semarang terutama tuna netra dan tuna daksa. Teknik penentuan informasi peneliti ditentukan dengan teknik purposive sampling menggunakan kriteriakriteria informan yang ditentukan oleh peneliti. Variabel yang digunakan dalam penelitian ini adalah fasilitas Trans Semarang yaitu tangga naik/turun, ramp, ruang untuk kursi roda/tempat duduk, dan tandatanda/singage. Serta variabel kendala yang meliputi kendala internal dan eksternal. Metode pengumpulan data diperoleh dengan metode observasi, wawancara, dan dokumentasi. Alat analisis yang digunakan dalam penelitian ini adalah analisis data deskriptif persentase.

\section{HASIL DAN PEMBAHASAN}

Beberapa permasalahan BRT adalah waktu tunggu yang masih cukup lama untuk 
kendaraan umum selain BRT, masih fasilitas shelter dan BRT yang masih menggunakan jalur yang sama dengan kurang nyaman dan ramah untuk kendaraan pribadi sehigga ketika terjadi difabel. Berdasarkan data yang telah kemacetan tidak ada bedanya dengan diolah, diketahui bahwa masih menggunakan kendaraan pribadi, kondisi banyak shelter yang belum shelter yang dan kurang nyaman karena memiliki ramp, sebagai berikut: masih banyak shelter portabel serta

Tabel 3. Kondisi Shelter Trans Semarang tiap koridor (satuan buah)

\begin{tabular}{|c|c|c|c|c|c|c|c|c|}
\hline No & Koridor & Curam & $\begin{array}{l}\text { Tanpa } \\
\text { Pegangan }\end{array}$ & $\begin{array}{l}\text { Tanpa } \\
\text { Ramp }\end{array}$ & Rusak & $\begin{array}{l}\text { Pohon/ } \\
\text { Tiang }\end{array}$ & Ramah & $\begin{array}{l}\text { Persentase } \\
\text { belum ramah }\end{array}$ \\
\hline 1 & I & 6 & 18 & 10 & 8 & 1 & 39 & $52,5 \%$ \\
\hline 2 & II & 3 & 2 & 7 & 3 & 4 & 41 & $31,6 \%$ \\
\hline 3 & III & 1 & 6 & 12 & 3 & 1 & 23 & $50 \%$ \\
\hline 4 & IV & - & 13 & 22 & 8 & 1 & 8 & $84,6 \%$ \\
\hline 5 & $\mathrm{~V}$ & - & - & 29 & - & - & 3 & $90,6 \%$ \\
\hline 6 & VI & - & - & 20 & - & - & - & $100 \%$ \\
\hline \multicolumn{2}{|c|}{ Jumlah } & $\begin{array}{l}10 \\
(3,4 \%)\end{array}$ & $39(13.3 \%)$ & $\begin{array}{l}100 \\
(34.2 \%)\end{array}$ & $\begin{array}{l}22 \\
(7,5 \%)\end{array}$ & $\begin{array}{l}7 \\
(2,3 \%)\end{array}$ & $\begin{array}{l}114 \\
(39,1 \%)\end{array}$ & $60,9 \%$ \\
\hline
\end{tabular}

Sumber: Data Primer, diolah

Berdasarkan data diatas dapat diketahui bahwa dari jumlah semua shelter sebanyak 292 buah terdapat beberapa shelter yang belum ramah difabel dari semua koridor diantaranya ramp yang curam sebanyak to buah atau 3,4\%, tangga atau ramp yang tidak memiliki pegangan sebanyak 88 buah atau 30,1\%, shelter yang tidak memiliki ramp sebanyak 51 buah atau sekitar 17,4\%, shelter/tangga/ramp yang rusak sebanyak 22 buah atau sekitar $7,5 \%$, tangga/ramp yang terdapat pohon atau tiang sebanyak 7 buah atau sekitar 2,3\%, dan shelter yang ramah difabel sebanyak 114 buah atau sekitar 39\%. Sehingga jika dijumlah maka shelter yang belum ramah difabel sebanyak 178 buah atau sekitar 6o,9\%.

Sedangkan untuk tiap koridor, shelter Trans Semarang yang belum ramah difabel sebanyak 52,5\% untuk koridor I, untuk koridor II sekitar 31,5\%, koridor III sekitar 50\%, koridor IV sekitar 84,6\%, koridor V sekitar 90,6\%, dan koridor VI sekitar 100\%.

Berdasarkan data diatas dapat diketahui bahwa dari 130 orang difabel yang menggunakan fasilitas Trans Semarang hanya sekitar 23 orang difabel atau sekitar 17,6\%. Dan sebagian besar difabel yang menggunakan fasilitas Trans Semarang adalah tuna netra. Hal 
ini membuktikan bahwa masih sedikit difabel dikarenakan akses pada Trans Semarang yang menggunakan fasilitas Trans Semarang masih belum nyaman dan ramah difabel.

Tabel 4. Pengguna Trans Semarang

\begin{tabular}{|c|c|c|c|c|}
\hline No & Kelompok & Pengguna & Bukan Pengguna & Jumlah \\
\hline 1 & Pertuni & 12 orang & 38 orang & 50 orang \\
\hline 2 & Kompak & 1 orang & 29 orang & 30 orang \\
\hline 3 & $\begin{array}{l}\text { Roemah } \\
\text { Difabel }\end{array}$ & 10 orang & 40 orang & 50 orang \\
\hline \multicolumn{2}{|c|}{ Jumlah } & 23 orang & 107 orang & 130 orang \\
\hline
\end{tabular}

Berdasarkan data diatas dapat diketahui bahwa dari 130 orang difabel yang menggunakan fasilitas Trans Semarang hanya sekitar 23 orang difabel atau sekitar 17,6\%. Dan sebagian besar difabel yang menggunakan fasilitas Trans Semarang adalah tuna netra. Hal ini membuktikan bahwa masih sedikit difabel yang menggunakan fasilitas Trans Semarang dikarenakan akses pada Trans Semarang masih belum nyaman dan ramah difabel.

\section{Fasilitas Shelter BRT dan Trans Semarang}

\section{Tangga naik/turun}

Hasil penelitian menunjukkan bahwa mayoritas shelter Trans Semarang masih belum aman dan nyaman terutama untuk difabel karena masih memiliki beberapa kekurangan seperti tidak ada pegangan, licin dan berlubang. Shelter Trans Semarang yang ada saat ini terdiri dari permanan dan portabel. Untuk shelter portabel, tangga merupakan satu-satunya akses untuk naik ke shelter karena sheletr portabel tidak mamilki ramp dan untuk sekarang baik permanen maupun portabel masih banyak yang belum memiliki pegangan sehingga belum dapat diakses oleh difabel.

\section{Ramp}

Hasil penelitian ini menunjukkan bahwa ramp masih memiliki banyak kekurangan yang awalnya bertujuan untuk memudahkan difabel untuk menggunakan fasilitas Trans Semarang tetapi pada kenyataannya difabel justru kesulitan untuk menaiki ramp tersebut. Sebagian besar shelter Trans Semarang tidak memiliki ramp terutama untuk koridor $\mathrm{V}$ dan koridor VI karena kedua koridor tersebut mayoritas masih menggunakan shelter portabel yang belum memiliki ramp. Oleh sebab itu shelter yang seharusnya ramah difabel tidak dapat dapat diakses dengan mudah.

\section{Ruang untuk kursi roda/tempat duduk}

Hasil penelitian ini menunjukkan bahwa fasilitas ruang untu kursi roda atau tempat duduk yang ada pada Trans Semarang disediakan hanya khusus untuk difabel, tetapi masih banyak masyarakat yang menggunakan fasilitas tersebut karena belum terlalu banyak difabel yang menggunakannya. Hal itu disebabkan karena ketidaktahuan difabel atau 
ketidaksesuaian fasilitas tersebut dengan difabel. Pemerintah sudah menyediakan fasilitas ruang untuk difabel tetapi hal tersebut masih dianggap kurang maksimal karena difabel masih merasa kesulitan menggunakan fasilitas Trans Semarang.

\section{Tanda-tanda atau singage}

Hasil penelitian ini menunjukkan bahwa fasilitas yang baik belum tentu bisa dimanfaatkan dengan baik karena masih ada orang yang tidak bertanggung jawab salah satunya adalah merusak fasilitas yang ada (melepas stiker). Tetapi memang tidak semua Trans Semarang masih memiliki tanda-tanda tersebut. Banyak tanda-tanda yang telah hilang dan belum diganti dengan yang baru. Pada dasarnya adanya tanda-tanda tersebut menunjukkan bahwa adanya ruang khusus yang tidak semua orang boleh menggunakannya, teapi karena kurangnya kesadaran dan kurang peduli masyarakat terhadap difabel maka fasilitas yang seharusnya untuk difabel masih belum bisa digunakan secara maksimal.

\section{Kendala-kendala difabel dalam mengakses Trans Semarang}

\section{Kendala internal}

Kendala yang dirasakan difabel dalam mengakses fasilitas Trans Semarang adalah susahnya akses pada shelter Trans Semarang. Fasilitas yang masih belum lengkap membuat difabel merasa kesulitan dan tidak berminat untu menggunakan fasilitas Trans Semarang. Shelter yang sebagian besar belum memiliki ramp menjadi salah satu kendala yang dihadapi oleh difabel. Selain itu beberapa difabel belum bisa bepergian secara mandiri dan harus didampingi sehingga mereka tidak menggunakan Trans Semarang.

\section{Kendala Eksternal}

Penentuan lokasi menjadi salah satu faktor penting dalam keberhasilan perencanaan karena dengan lokasi yang sesuai maka shelter yang sesuai dengan ketentuan akan terwujud. Akan tetapi masih banyak yang shelter yang masih belum sesuai dengan ketentuan karena lokasi penempatan shelter yang kurang memadai. Bebrapa faktor diantaranya perbaikan jalan yang menyebabkan perubahan penempatan shelter, keterbatasan lahan yang bisa memengaruhi jenis dan kualitas shelter, kondisional penumpang yang menyebabkan perubahan titik penempatan shelter.

Pertimbangan-pertimbangan tersebut akan sangat berpengaruh terhadap perubahan perencanaan seperti lokasi penempatan shelter yang berubah dan bentuk shelter yang berubah. Sehingga fasilitas yang sebelumnya sudah disesuaikan dengan ketentuan yang ramah difabel karena kondidi lapangan yang kurang mendukung maka fasilitas yang dibangun tidak bisa sesuai dengan ketentuan yaitu fasilitas yang ramah difabel.

Keterbatasan anggaran yang menyebabkan pembangunan fasilitas Trans Semarang terhambat seperti pengadaan shelter permanen.

\section{SIMPULAN}

Berdasarkan hasil penelitian dan analisis data yang telah dilakukan, maka dapat ditarik kesimpulan bahwa: Fasilitas shelter dan Trans Semarang yang masih belum memenuhi ketentuan yang ada. Hal tersebut dapat dilihat 
dari kesulitan difabel dalam mengakses fasilitas Trans Semarang. Ketidaksesuaian fasilitas yang ada dengan ketentuan menyebabkan fasilitas tersebut menjadi tidak ramah difabel. Fasilitas yang masih kurang ramah difabel diantaranya tangga yang masih licin dan tidak memiliki pegangan, ramp yang masih curam, penggunaan shelter portabel yang tidak ramah difabel, beberapa bus yang tidak memiliki ruang untuk kursi roda, serta beberapa bus yang masih belum memiliki tanda atau singage terkait fasilitas prioritas untuk difabel. Sebagian besar shelter yang belum ramah difabel disebabkan belum adanya ramp yaitu sekitar $34.2 \%$ dan koridor yang masih belum ramah difabel adalah koridor VI karena masih menggunakan shelter portabel.

Kendala internal yang dihadapi difabel dalam mengakses Trans Semarang adalah difabel masih belum merasa aman dan nyaman untuk menggunakannya karena masih banyak shelter yang belum ramah difabel, sedangkan kendala internalnya adalah kondisi lapangan yang mudah berubah karena perbaikan jalan, keterbatasan lahan dan kondisional penumpang, perubahan rencana pembangunan dari Bappeda ke Dinas Perhubungan karena terjadi pertimbangan setelah pengecekan lapangan, serta keterbatasan angggaran untuk menyelesaikan program sehingga pemerintah menggunakan shelter portabel untuk mengantisipasi belum adanya shelter permanen pada beberapa titik.

\section{DAFTAR PUSTAKA}

Badan Pusat Statistika Kota Semarang. (2016). Kota Semarang Dalam Angka 2016. Kota Semarang. Badan Pusat Statistika.

Keputusan Menteri Pendayagunaan Aparatur Negara Nomor 63 Tahun 2003 tentang Pedoman Umum Penyelenggaraan Pelayanan Publik.

Keputusan Menteri Pekerjaan Umum Nomor 30/PRT/M/2006 tentang Pedoman Teknis Aksesibilitas pada Bangunan Umum dan Lingkungan.

Nurfitrokha, Yunilia. 2017. Strategi Transportasi Berkelanjutan di Kota Semarang. Skripsi. Semarang: Fakultas Ekonomi Universitas Negeri Semarang.

Sanapiah Azis. (2000). Pelayanan yang Berorientasi Kepada Kepuasan Masyarakat. Jurnal Administrasi Negara. Vol . 6 Nomor 1.

Setiasih, Tri Rina dan Sebayang, K. Lesta. (2017). Analisis Kebijakan Earmarked Tax Pajak Kendaraan Bermotor sebagai Upaya Peningkatan Pelayanan Publik (Pembangunan dan Pemeliharaan Jalan) di Provinsi Jawa Tengah. EDAJ, Volume 7, Nomor 1, Februari 2018. Semarang: Jurusan Ekonomi Pembangunan, Fakultas Ekonomi, Universitas Negeri Semarang.

Undang-Undang Dasar Tahun 1945 Pasal 27 ayat (2) http://jateng.tribunnews.com/2016/11/o7/banyakfasilitas-umum-belum-ramah-difabel-sugenglapor-ombudsman (Diakses pada tanggal 20 April 2017)

https://mediajateng.net/2016/o4/19/fasum-kotasemarang-tak-ramah-difabel/230o/ (Diakses pada $\begin{array}{llll}\text { tanggal } & 20 & \text { April }\end{array}$ 